\title{
Ser ou não ser... um marionetista
}

\section{To Be or Not to Be... a Professional Puppeteer}

Anca Doina Ciabotaru ${ }^{1}$ 


\section{Resumo}

Qual a formação profissional para o marionetista? Neste relato exponho uma perspectiva das diferentes possibilidades de formação deste profissional na Romênia.

Palavras-chave: Marionetista profissional; formação do marionetista; teatro de animação

\section{Abstract}

What is the professional training for the puppeteer? In this report I present a perspective of the different possibilities of training of this professional in Romania.

Keywords: Professional puppeteer; training of the puppeteer; animation theatre 
Ser um marionetista profissional implica - na teoria e na prática - em dois aspectos determinantes: uma formação específica e ser pago por exercer essa arte. Tradicional ou vanguardista, indiferente do tempo ou das coordenadas de tempo-espaço, o teatro de animação é definido não apenas pela estrutura da expressão no palco, mas também pelo plano da formação dos marionetistas e seu estatuto. Afastar-se da tradição em direção à vanguarda está sujeito à divergência entre o estilo do discípulo do estilo do seu mestre.

A formação do marionetista (e não apenas a formação) requer que se use HOJE as técnicas de um ONTEM mítico, para um mítico AMANHÃ! Aceitando essa hipótese, o seu estudo ou a sua constante formação/melhora acaba se tornando um processo desafiador, cujo paradoxo é vivido pelo professor/mentor: ele não alcançará notoriedade a não ser que os discípulos encontrem seus próprios meios, mas ele os treina mostrando o caminho que ele mesmo trilhou. As técnicas usadas para construir e animar marionetes tornaram-se mais variadas em virtude dessas cisões - entre o que é oferecido a alguém ao ser iniciado na arte do teatro de marionete, e o que será oferecido por ele no decorrer de toda sua jornada profissional.

Portanto, a vanguarda torna-se uma releitura sintética e melhorada da tradição. Esse distanciamento é possível apenas se o marionetista admitir que isso não culminará na traição de valores imutáveis de sua arte e da comunidade a qual pertence, comunidade essa que - de fato - lhe paga. Vincular o eixo de seus valores pessoais aos do público é o aspecto que determina a aceitação do intercondicionamento entre os valores do marionetista e seu estatuto, uma falta de congruência entre eles geraria... kitsch. Arte pode apenas nascer do desejo de pesquisar, desenvolver e melhorar a forma de expressão que representará a identidade do marionetista, em concordância com seu programa estético, assim como seu nível de consciência.

De maneira geral, estudos na área de desenvolvimento pessoal e de aprendizado de técnicas enfatizaram o fato de que "nossos resultados não representam nosso potencial, mas sim o atual nível de consciência de nosso potencial". Portanto, formação étnica torna-se uma condição necessária, mas não suficiente. Há mais três variáveis nessa equação: intuição, criatividade, consciência. Embora todos os marionetistas tenham as mesmas seis faculdades mentais: percepção, razão, memória, vontade, intuição e imaginação, nem todos estão cientes do modo como as usam. Não importa o quão paradoxal possa parecer, até mesmo marionetistas podem imaginar: "O que você mais usa: intuição ou razão"?

A arte de teatro de animação nasce não apenas do desejo do marionetista de performar (fazer arte pelo valor artístico), mas também pelo seu desejo de ser bem-sucedido, de se expressar e de realizar criações significativas. Na correlação desses aspectos com sua formação profissional, quando estiverem estabelecendo seus objetivos, seus sonhos, marionetistas terão escolhido entre VIVER O FUTURO e O CONFORTO DE EXPERIÊNCIA ADQUIRIDA/ TÉCNICAS APRENDIDAS. A opção faz a diferença... Pode determinar sucesso. Dadas essas condições, uma nova questão surge: Que tipo de formação pode garantir sucesso?

1. Formação tradicional, baseada na relação entre pai/mestre e aprendiz usada no teatro tradicional família/clã? 
2. Formação técnica, baseada no programa estético de um grupo de teatro/ instituição?

3. Formação universitária, baseada na missão/visão de um programa que é subordinado a uma política educacional?

4. Formação autodidata, baseada em intuição e paixão?

\section{Aqui há vários exemplos:}

\section{Formação que é baseada na tradição em/e modernidade}

Páginas do diário. Lugar: Índia - Jaipur (Palácio da cidade). O chefe da companhia é um membro do duo orquestral (depois eu descobriria que ele também sabia construir e animar marionetes); o jovem marionetista/aprendiz está longe das vistas do público, atrás do painel, ao lado de suas marionetes kathpitli, pronto para responder às perguntas do mestre. Sentei-me nas escadas e assisti não uma performance, mas uma aula sobre como adaptar uma arte tradicional às exigências dos, ainda que apressados, curiosos espectadores-visitantes. O Dançarino, Michael Jackson (usando uma máscara tradicional), e $O$ Domador de Cobras foram anunciados e, cada um na sua vez, dançaram três números em três minutos, repetindo toda vez que havia um pedido. Marionetistas/fabricantes de marionetes sabem que só podem sobreviver se encontrarem múltiplas variantes: durante o dia se apresentam no museu e vendem marionetes, e durante a noite se apresentam onde quer que sejam convidados hotéis, casas de família, eventos variados.

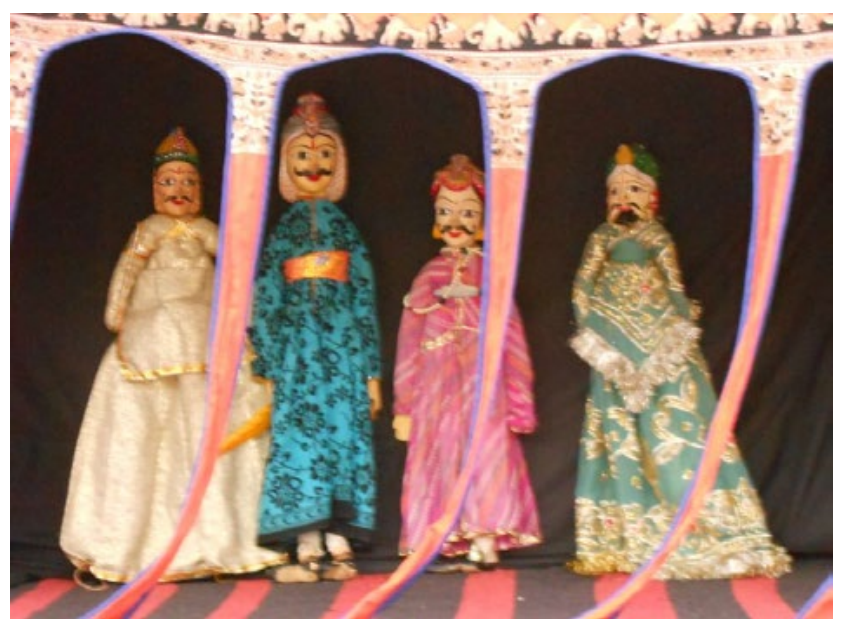

Kathputli - Jaipur - Índia. Acervo: Inca Doina Ciobotaru

Encontrei o mesmo sistema em Nova Deli (Índia) - os membros da companhia pertenciam à mesma família estendida. A cena musical é garantida pelos membros femininos, que - quando não estão se apresentando - fazem as fantasias das marionetes (para performances ou para vendas). A capital da cidade os fornece uma oportunidade que eles não desperdiçam: televisão. Porque compartilho do seu ofício, mostraram-me, como bônus, muitos comerciais feitos com marionetes. Tive a impressão de que 
o espírito da tradição era seguido de perto por Jim Henson (1936-1990). A formação dentro-do-clã é uma receita que (ainda) funciona e, de fato, representa um estilo de vida; não importa o quão presa no mito da tradição possa parecer, é governada pela lei universal da vibração de energias específicas para cada período de tempo - que tira de um, e igualmente molda noutro sutil e (algumas vezes) imperceptível caminho. A arte do marionetista, assim como de qualquer artista, pode apenas ser completa quando é recebida por uma plateia que esteja disposta a contribuir. Essa regra não pode ser driblada pelo marionetista que cai no caminho da tradição. Não importa o quão forte, a tradição eventualmente irá ceder às tendências dos tempos que manifesta, embora esse processo seja condicionado à influência de programas educacionais.

\section{Formação técnica, baseado no programa estético de um grupo ou instituição teatral}

Esse tipo de formação garantiu o desenvolvimento de carreiras de numerosas gerações de marionetistas romenos. Entre os anos de 1950-1989, no Ţăndărică Theatre em Bucareste (embora não exclusivamente lá) eram realizados estágios de formação profissional/"reciclagem" - cursos intensivos de curta duração que eram ministrados pelos diretores, atores, coreógrafos com atividade profissional de prestígio, mas... complementados com cursos em ideologia política. Algumas vezes, artistas estrangeiros recebiam convites para ministrar cursos de maestria artística como, por exemplo, os cursos de pantomima ministrados por Marcel Marceau (1923-2007).

Depois de 1989, mesmo existindo numerosos teatros de marionetes ao redor do mundo que organizem cursos de treinamento de curta duração, tanto para profissionais quanto para marionetistas amadores, esses treinamentos são - parcialmente - realizados pelas universidades, na forma de Programas de Mestrado... Que duram dois anos. Instituições teatrais (cuja maioria é financiada pelo Estado) abandonaram a organização de estágios de formação profissional. Nesse contexto, é válido notar que em laşi, durante o Festival Internacional de Teatro para Jovens e Crianças, organizado pelo Luceafărul Theatre anualmente, há oficinas que criam oportunidade de encontros profissionais que podem perturbar rotinas e reanimar espíritos criativos.

A existência de Centros de pesquisa/criação, de programas de masterclass e oficinas realizadas por artistas prestigiados, provam que não importa a evolução da relação entre mestre/aprendiz e as novas formas de tutoria a que foram levados, sua essência permanece imutável: a dupla necessidade - encontro e compartilhamento de conhecimento, evolução profissional está condicionada à relação entre a experiência e procura por novas soluções, no lado de quem é aprendiz.

\section{Formação universitário, baseada na missão/visão de um programa é que subordinado a uma política educacional}

Darei o exemplo de um programa de três anos de formação em A Arte de Atuar, Bonecos e Marionetes, realizado na Faculdade de Teatro da Universidade de Artes "George Enescu" em laşi, de cujo desenvolvimento tenho participado pelos últimos dezessete anos. Alunos têm a chance de aprender as principais técnicas de animação 
(objetos animados, bonecos de luva, marionetes bunraku, teatro de sombras, bonecos de boca articulada), assim como de atuação (com tudo que implica: discurso de palco e movimento, combate de palco, canto, etc.). Nossas performances experimentais são oficinas criativas, nas quais os alunos exploram a possibilidade de usar meios de expressão contemporâneos, começando dos clássicos.

Nossa filosofia é: você não pode ser um bom marionetista se você não é, primeiramente, um bom ator.

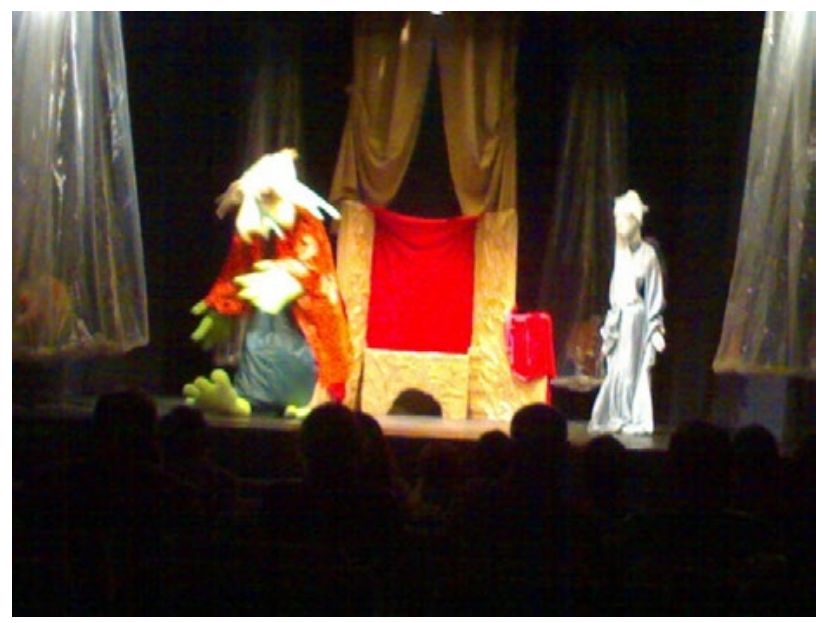

Butterfly. Direção e acervo de Anca Doina Ciabotaru

A diferença entre sistemas universitários pode ser estabelecida pelos resultados dos graduados. Não é apenas o orçamento que faz a diferença, mas o recurso humano - as equipes que asseguram a formação dos alunos, e suas vontades de continuarem se especializando, para procurar soluções harmonizando identidades artísticas com a suposta missão.

\section{Formação autodidata, baseado em intuição e paixão}

Esse tipo de treinamento fecha o círculo. É exclusivamente determinado pelo desejo ardente do marionetista de performar, de se expressar, de ter um impacto no público. Além das coordenadas de tempo-espaço, a vida do marionetista será determinada pelo modo como ele lida com os desafios do contexto sociocultural do qual ele pertence. Uma das palavras centrais desse século é orçamento, que pode ser tanto uma obsessão quanto um desafio. Quanto esse produto custa? Quem deveria ser responsável por levantar o dinheiro? Se o marionetista encontrar um patrocinador, o que deveria oferecer em troca? Essas questões obsessivas são familiares em todo lugar, elas parecem ter conquistado o mundo. E, no entanto, sucesso pode ser dificultado. Analisando a relação entre a criatividade e a tentativa de alcançar seu máximo potencial, John Maxwell, um dos mais conhecidos autores de literatura motivacional, escreveu que:

O maior obstáculo para alcançar o sucesso é o fato de que nós dependemos de sucessos passados. [...]. Eu quase nunca penso sobre os prêmios e reconhecimento que recebi no passado. Estou feliz com eles, mas percebo que você só é honrado por méritos passados. Eu sempre me pergunto o que estou fazendo no presente. 
É uma ideia que vale a pena ser refletida.

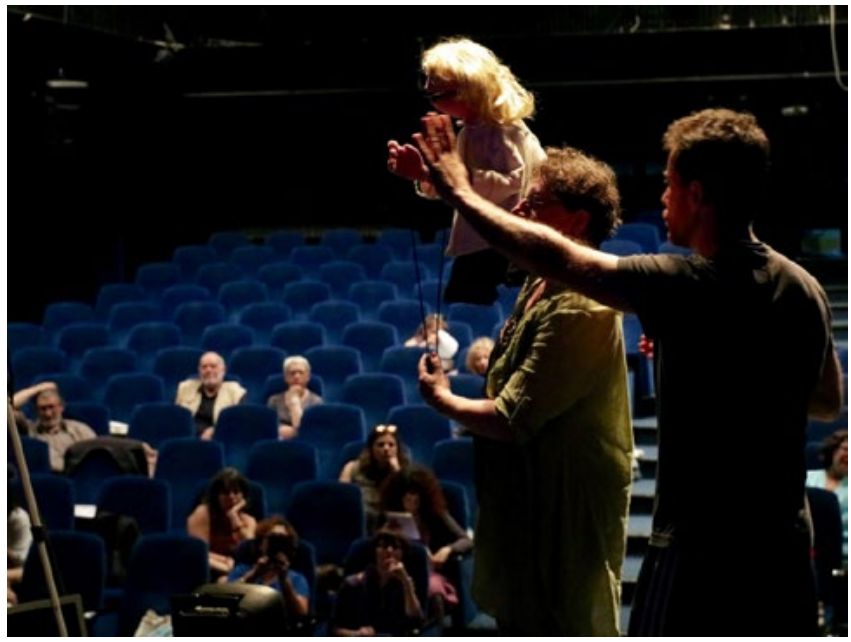

Oficina - Târgoviște, Romênia - Acervo: Anca Doina Ciabotaru

O trio: imaginação, imagem do palco e imaginário, também governa a arte da marionete. Duelar excessivamente para resolver problemas da realidade, e não da imaginação, pode bloquear criatividade. Descobrir a "receita de sucesso" pode ser o ponto de partida do fracasso, a não ser que esteja respaldado pela contínua procura e pela vontade de desistir de algo que deu certo anteriormente. Excelência é possível apenas se trouxer também uma inquietação iniciante, não importa o nível técnico de maestria.

Começando por esses exemplos, podemos aceitar o fato de que a história do teatro de marionetes é duplicada pela história do treinamento profissional de marionetistas. Não importa o tipo de formação, os aspectos técnicos, esse tipo de programa implica no enfoque da personalidade inteira do marionetista, de todo e cada traço definitivo (resistência física, habilidade de lidar com emoções, resolver criativamente problemas, construir relações humanas, transformar projetos em realidade), mas também na existência do desejo de criar impacto aos expectadores.

O primeiro passo para encontrar as respostas é... Levantar perguntas. O tipo ideal de formação profissional é o que faz você se sentir realizado.... Como SER HUMANO.

Este texto traduzido, do inglês, por Larissa Ceres Rodrigues Lago, também se encontra publicado em inglês neste número do periódico. Doutoranda pelo Programa de Pós-graduação em Estudos da Tradução, Universidade Federal de Santa Catarina (UFSC). lariceres@gmail.com

Recebido em: 29/06/2018

Aprovado em: 29/06/2018 